\begin{tabular}{|c|l|}
\hline Title & Variation of Saturated Surface Density of Oval bumin on Bubble Surface in Continuous Foam Separation \\
\hline Author(s) & Maruyama, Hideo; Seki, Hideshi; Suzuki, A kira; Inoue, Norio \\
\hline Citation & $\begin{array}{l}\text { Journal of Colloid and Interface Science, 299(1), 416-420 } \\
\text { https://doi.org/L0.1016/.jcis.2006.02.006 }\end{array}$ \\
\hline Issue Date & 2006-07-01 \\
\hline Doc URL & http://hdl.handle.net/2115/8539 \\
\hline Type & article(author version) \\
\hline File Information & maruyama_etal_06_JCIS_inpress.pdf \\
\hline
\end{tabular}

Instructions for use 


\title{
Variation of Saturated Surface Density of Ovalbumin on Bubble Surface in Continuous Foam Separation
}

\author{
Hideo Maruyama*, Hideshi Seki, Akira Suzuki and Norio Inoue \\ Division of Marine Biosciences, Graduate School of Fisheries Sciences, Hokkaido \\ University, Minato 3-1-1, Hakodate, JAPAN 041-8611 \\ Telephone: +81(138)408813; Facsimile: +81(138)408811; E-mail: \\ maruyama@elsie.fish.hokudai.ac.jp \\ *Corresponding author. \\ E-mail address: maruyama@elsie.fish.hokudai.ac.jp (H. Maruyama)
}




\begin{abstract}
The adsorption of ovalbumin (OA) onto the bubble surfaces was studied with various pHs (3.5, 4.6, 6.0 and 8.0) by a continuous foam separation technique. From the value of the saturated surface density of adsorbed OA, the variation of effective diameter $(D)$ of an OA molecule on the bubble surface was estimated for various $\mathrm{pHs}(3.5,4.6,6.0$ and 8.0$)$ of the OA solutions, assuming that the cross-section of the OA molecules be circular and that the OA molecules adsorb on the bubble surface in a closest packing structure. The estimated variation of $D$ with $\mathrm{pH}$ was attempted to explain based on a model modified from that proposed by Pujar and Zydney [33]. The modified model could well reproduce the variation of the effective diameter with $\mathrm{pH}$; the values of $D$ calculated on the basis of the modified model almost agreed with that estimated from the saturated surface density in the present experimental $\mathrm{pH}$ range. From these, conclusion was drawn that the modified model presented in this study can express the variation in the effective diameter with $\mathrm{pH}$.

Keywords: Foam separation; Saturated surface density; Ovalbumin; Effective diameter; Surface charge
\end{abstract}




\section{Introduction}

Foam separation is a method of enriching or removing various surface-active substances minutely dissolved in water. This technique has been studied in many fields, such as chemical/biochemical engineering [1-6], analytical chemistry [7, 8], wastewater treatment [9-11] and so on.

In our previous study [6], the enrichment of ovalbumin and hemoglobin used as model substances from aqueous solutions were attempted by a foam separation method in a continuous system. The adsorption of the soluble proteins onto the bubble surfaces well followed the Langmuir's adsorption isotherm, and as a result we could obtain the two adsorption parameters, i.e., adsorption equilibrium constant and saturated adsorption density. Because these parameters were remarkably varied with $\mathrm{pH}$ of the solution, it was suggested that the variation in the dissociation state of the amino- and carboxyl-groups in the amphoteric macromolecules with $\mathrm{pH}$ and the resulted variation in the electric charge of the macromolecules is closely related to the behavior of the adsorption onto the bubble surface. The influence of $\mathrm{pH}$ both on protein adsorption behavior and on the state of the adsorbed protein molecules on bubble surfaces is important not only for foam separation technique but also for emulsification [12,13], foam stability [14-18], food processing [19,20], and so on.

In this paper, the authors concentrate its focus on the variation of the saturated surface density of ovalbumin adsorbed on bubble surfaces with $\mathrm{pH}$ and attempt to determine a sphere-equivalent effective diameter of albumin molecules in the saturated adsorption. The variation will be discussed on the 
basis of the dissociation of the residual amino- and carboxyl-groups in the protein molecule. 


\section{Materials and method}

\subsection{Materials}

Ovalbumin from egg white (OA) was purchased from Difco Laboratories and was used without further purification. The ion strength and $\mathrm{pH}$ of the solutions were adjusted with a $\mathrm{NaCl}$ solution to $5 \times 10^{-3} \mathrm{M}$ and with aqueous $\mathrm{HCl}$ or $\mathrm{NaOH}$ solutions to several desired $\mathrm{pH}$ values, respectively. All experiments were carried out at room temperature and under atmospheric pressure. All the other chemicals were analytical grade reagents.

\subsection{Experimental setup}

The experimental setup for foam separation is almost the same as that used in the previous study $[6,21,24]$. A schematic diagram of the experimental setup is shown in Fig. 1. A bubble column of $4.4 \mathrm{~cm}$ in inside diameter and 0.6 or $0.95 \mathrm{~m}$ in height was employed. The column was made of transparent acrylic resin. Sintered glass filter (10-15 $\mu \mathrm{m}$ mean-pore size) was installed as a gas distributor at the bottom of the column. The foam collector was equipped at the top of the column to entrap the liquid in the foam generated from the liquid surface. The collector was also made of an acrylic resin cylinder $4.8 \mathrm{~cm}$ in height and $5.0 \mathrm{~cm}$ in inside diameter (i.e., the outside diameter of the foam separation column), the bottom end of the cylinder being covered with a stainless steel net. The collector was filled with a certain amount of polyester fiber wool and fixed at the top of the foam separation column. Pressure taps for measuring gas holdup in the column were installed along the wall at intervals of $25 \mathrm{~cm}$. 


\subsection{Experimental procedure}

The procedure for measuring the flow rate of the liquid in foam was the same as it described in the previous study [6, 21, 24]. The OA solution prepared at a desired concentration or $\mathrm{pH}$ was stored in a storage tank. The solution was charged into the column from a feed tap by a pump (see Fig.1). The volumetric flow rate of the feed liquid was kept constant as $0.5 \mathrm{~cm}^{3} / \mathrm{s}$. After the column was filled with the solution, nitrogen gas was supplied and was dispersed as bubbles by the distributor. The foam height, which corresponds to the distance between the liquid-foam interface and the top of the foam surfaces in the column, was adjusted by controlling the volumetric flow rate of the drain liquid measured by a rotameter. The bulk liquid in the column was sampled from the bottom of the column.

After a steady state was attained (ca. 2 hr was enough for the attainment in almost every run), the samplings of liquid in the foam for measuring the volumetric flow rate, $W_{\mathrm{f}}$, of liquid in the foam and the protein concentration, $C_{\mathrm{f}}$, in the collapsed foam liquid were started. The $W_{\mathrm{f}}$ was measured as follows. The collector was attached on the top of the column to collect the upwardly flowing foams generated from the liquid surface. After ca. $15 \mathrm{~s}$, the collector was detached from the column and its weight was measured by a balance. This procedure was repeated five times using five collectors (for ca. 6 minutes). $W_{\mathrm{f}}$ was determined from the change in the collector's weight for the collecting time, assuming that the density of the liquid in the foam was nearly equal to that of water. After changing the foam height within the column, the experiments were repeated. 
The intrinsic flow rate, $W_{\mathrm{f} 0}$, and the concentration, $C_{\mathrm{f} 0}$, of the liquid in the foam at the liquid-foam interface within the column were determined by the extrapolation method [6, 23]; plots of the logarithms of $W_{\mathrm{f}}$ and $C_{\mathrm{f}}$ versus the foam height yielded two straight lines with negative and positive slopes, respectively. The extrapolations of the two lines back to the foam height $=0$ gave $W_{\mathrm{f} 0}$ and $C_{\mathrm{f} 0}$.

The gas holdup was determined from the difference in static pressure between the clear and aerated liquids using a differential pressure transducer (Tem-Tech Lab. Inc., JAPAN). The voltage signals from the transducer were recorded by a personal computer (NEC PC-9801VM) via A/D converter (CONTEC).

The concentrations of the proteins were measured by the Lowry method [22]. The $\mathrm{pH}$ of the bulk liquid in the column was measured with a $\mathrm{pH}$ meter (ORION Model SA 520). 


\section{Results and discussion}

\subsection{Determination of adsorption parameters}

In the bubble dispersed phase with the column, the following mass balance is obtained under a steady state at the liquid - foam interface [6]:

$W_{\mathrm{f} 0} C_{\mathrm{f} 0}=S_{\mathrm{b}} X+W_{\mathrm{f} 0} C_{\mathrm{b}}$

where, $C_{\mathrm{b}}, S_{\mathrm{b}}$, and $X$ denote the protein concentration in the bulk liquid, the production rate of bubble surface area in the column and the surface density, respectively. From Eq.(1) and Lagmuir’s adsorption isotherm,

$X=\left(W_{\mathrm{f} 0} / S_{\mathrm{b}}\right)\left(C_{\mathrm{f} 0}-C_{\mathrm{b}}\right)=K \gamma C_{\mathrm{b}} /\left(1+K C_{\mathrm{b}}\right)$,

where, $K$ and $\gamma$ are the adsorption equilibrium constant and the saturated surface density, respectively. The production rate of bubble surface area in the column, $S_{\mathrm{b}}$, is expressed by the following equation [23];

$S_{\mathrm{b}}=6 A \varepsilon_{\mathrm{G}}\left(1-\varepsilon_{\mathrm{G}}\right)^{4.65}\left\{(4 / 225)\left(\rho_{\mathrm{L}}-\rho_{\mathrm{G}}\right)^{2} g^{2} /\left(\mu_{\mathrm{L}} \rho_{\mathrm{L}}\right)\right\}^{1 / 3}$,

where $A, \varepsilon_{\mathrm{G}}, g, \rho_{\mathrm{L}}, \rho_{\mathrm{G}}$ and $\mu_{\mathrm{L}}$ denote a cross-sectional area of the column, the gas holdup, the gravitational acceleration rate, the densities of the liquid and the gas and the viscosity of the liquid, respectively.

Fig. 2 shows the adsorption isotherm of ovalbumin. Previous data [6] are 
also presented in the same figure (pH 3.5, 4.6 and 6.0). Solid lines in Fig. 2 are calculated by using $K$ and $\gamma$ here obtained. Table 1 lists the values of $K$ and $\gamma$ for each $\mathrm{pH}$. Hunter et al. investigated the adsorption of lysozyme at air-water interface by using radiolabeling technique [24]. They reported that the adsorption kinetics and the adsorption equilibrium followed Lamgmuir adsorption model. Further, Razumovsky and Damodaran [25] reported that the adsorption of acidic subunits of soy 11S globulin (AS11S) and bovine serum albumin (BSA) followed Langmuir isotherm. These fundamental studies support our assumption that the adsorption of the here studying proteins be also Langmuir-type.

3.2 Variation of effective diameter for ovalbumin on the bubble surface with $\mathrm{pH}$ in the saturated state of adsorption

Assuming that the cross-section of the ovalbumin molecules be circular and that the molecules adsorb on the bubble surface in a closest packing structure (packing fraction, $\phi=0.907$ ) in the saturated state of the adsorption, the diameter, $D$, of the molecules can be calculated from $\gamma$ as $[6,26]$ :

$$
\frac{M_{\mathrm{w}}}{L \gamma}=\frac{\pi}{4} D^{2} \cdot \frac{1}{\phi}
$$

By solving with respect to $D$,

$$
D=2 \sqrt{\frac{\phi M_{\mathrm{w}}}{\pi L \gamma}},
$$


where $L$ and $M_{\mathrm{w}}$ denote the Avogadro's number and the molecular weight, respectively. The values of $D$ at each $\mathrm{pH}$ were calculated using 45,000 as the $M_{\mathrm{w}}$. The calculated diameters at each $\mathrm{pH}$ are also listed in Table 1 . These effective diameters are considered to be influenced by the lateral forces acting among the adsorbed molecules, i.e., an electrostatic repulsive force and the van der Waals attractive force $[27,28]$. From Table 1 , we can see that the value of $D$ becomes the smallest at $\mathrm{pH} 4.6$ with the increase of $\mathrm{pH}$. This $\mathrm{pH}$ value just corresponds to the isoelectric point (i.e.p.) of the protein. This is in a sence a natural consequence because the electrostatic repulsive force acting between any two protein molecules can be considered to be weakest at this $\mathrm{pH}$. Matsumoto and Inoue [29] reported that an ovalbumin molecule in an aqueous environment is almost spherical and its diameter ca. $50 \AA$ based on small-angle X-ray scattering (SAXS) measurement. Stein et al. [30] reported that crystal structure dimensions of ovalbumin were $70 \times 45 \times 50 \AA$. These reported values are almost in agreement with the $D$ value above calculated at $\mathrm{pH} 4.6$ in this study. Thus, it is reasonable that ovalbumin molecules have a closest-packed structure on the bubble surfaces in the saturated state. Moreover this result also supports the validity of our method of determing the adsorption density and the employment of Langmuir's isotherm. In the previous paper, the tendency of change in $D$ with $\mathrm{pH}$ was qualitatively explained by the modified net-charge model based on the model developed by Tanford et al. [31] and Scatchard et al. [32]. In the present paper, the same problem is attempted to discuss more quantitatively.

Pujar and Zydney [33] conducted size-exclusive chromatography and 
membrane filtration (polyethersulfone membrane) of bovine serum albumin (BSA) and developed a model for estimation of the effective radius, $R_{\mathrm{eff}}$, of BSA;

$R_{\mathrm{eff}}=r_{\mathrm{s}}+\frac{4 r_{\mathrm{s}}^{3} \sigma_{\mathrm{s}}^{2}}{\varepsilon \varepsilon_{0} k k T} \lambda(1-\lambda)$,

$\lambda=r_{\mathrm{s}} / r_{\mathrm{p}}$,

where $r_{\mathrm{s}}$ and $r_{\mathrm{p}}$ represent radius of a solute molecule and a pore, respectively, and $\varepsilon, \varepsilon_{0}, \kappa, k, \sigma_{\mathrm{s}}$ and $T$ are the dielectric constant of the bulk solution, the permittivity of free space, the Debye length, the Boltzmann constant, the surface charge density of solute and the temperature, respectively. They discussed the results taking into account an electrostatic interaction between a solute molecule and the surface of a cylindrical pore. This relationship seems to mostly correspond with that of the electrostatic interaction between an ovalbumin molecule adsorbed on bubble surface and the surrounding ovalbumin molecules in the saturated state with a closest packing. By applying Eq. (5a) to the present study, the effective diameter of an ovalbumin molecule can be expressed as:

$$
\begin{aligned}
& D=r_{\mathrm{s}}\left(1+8 C_{1} \sigma_{\mathrm{s}}\right), \\
& C_{1}=\frac{r_{\mathrm{s}}}{\sqrt{8 \varepsilon \varepsilon_{0} k k T}} .
\end{aligned}
$$

Since $\sigma_{\mathrm{s}}$ comes from the net charge, $z$, of ovalbumin molecules, a relation 
should hold between these two [6] as:

$\mathrm{z}=\left(1-\alpha_{\mathrm{a}}\right) N_{\mathrm{a}}+\left(1-\alpha_{\mathrm{g}}\right) N_{\mathrm{g}}+\left(1-\alpha_{\mathrm{c}}\right) N_{\mathrm{c}}-\alpha_{\mathrm{i}} N_{\mathrm{i}}-\alpha_{\mathrm{p}} N_{\mathrm{p}}-\alpha_{\mathrm{t}} N_{\mathrm{t}}$

where $N$ and $\alpha$ denote the number of the residual acidic and basic functional groups in the protein molecule and the dissociation degree of the functional groups. Subscripts "c", "p", "t", "a", "g" and "i" express the carboxyl-, phenolic hydroxyl-, thiol-, animo-, guanidine- and imidasol-groups, respectively. Thus, $\sigma_{\mathrm{s}}$ can be expressed as:

$\sigma_{\mathrm{s}}=C_{2}|\mathrm{z}|$,

where, $C_{2}$ is a proportional constant. Because, in the present study, the temperature and the ionic strength of the ovalbumin solution was kept constant and $r_{s}$ in Eq. (6b) can be regarded as $0.5 D$ at i.e.p. where an ovalbumin molecule will be most compact and spherical in shape to give the smallest size $\left(r_{\mathrm{s}}=0.5 D_{\text {iep }}=25.2 \AA\right), C_{1}$ in Eqs.(6) can be evaluated as $C_{1}=3.42 \times 10^{1} \mathrm{~m}^{2} / \mathrm{C}$. Using Eqs. (6), (7) and (8), the variation of $D$ with $\mathrm{pH}$ can be estimated by giving an adequate value of $C_{2}$. The solid line in Fig. 3 was obtained by fitting to the experimental data by a least-squares method, in which the value of $C_{2}=$ $1.53 \times 10^{-4} \mathrm{C} / \mathrm{m}^{2}$ was used. The model calculation can well reproduce the experimental data, although some deviation is observed between the experimental and the calculated values at $\mathrm{pH}$ 3.5. The values of $N$ and $\mathrm{pK}$ used for the calculation of $z$ are listed in Table 2. The minimum value of $D$ calculated was given at $\mathrm{pH}$ 4.3. This is affected by the calculation of $z$ (i.e., the 
used values of $p K)$ and the used values of $N$. The good agreement between the experimental and the calculated values of $D$ suggests that the model developed by Pujar and Zydney [33] can also be applied to the estimation of the effective diameter of ovalbumin molecules adsorbed on bubble surfaces in the saturated state. A further study will be necessary about the relation between the saturated adsorption state of foams and their stabilities. 


\section{Conclusions}

The effective diameter of ovalbumin molecules adsorbed on bubble surfaces was evaluated from the value of saturated adsorption density on the assumption that the molecules be adsorbed in a closest packing structure at saturated adsorption state. When the $\mathrm{pH}$ of the ovalbumin solution was varied, the evaluated diameter of ovalbumin molecules became the smallest at the isoelectric point of ovalbumin (i.e., pH 4.6). This variation of the diameter with pH was attempted to explain based on a model modified from that proposed by Pujar and Zydney [33]. It was found that the experimentally obtained value of the diameter can almost be reproduced by the calculation on the basis of the modified model. From these, conclusion was drawn that the modified model presented in this study can express the variation in the effective diameter with $\mathrm{pH}$. 


\section{Notation}
A = a cross sectional area of bubble column
$\left[\mathrm{m}^{2}\right]$
$C_{1} \quad=$ a parameter defined by Eq. (6b)
$\left[\mathrm{m}^{2} / \mathrm{C}\right]$
$C_{2} \quad=$ a proportional constant
$\left[\mathrm{C} / \mathrm{m}^{2}\right]$
$C_{\mathrm{b}} \quad=$ concentration of the bulk liquid in bubble column
$\left[\mathrm{kg} / \mathrm{m}^{3}\right]$
$C_{\mathrm{f}} \quad=$ concentration of the liquid in foam
$\left[\mathrm{kg} / \mathrm{m}^{3}\right]$
$C_{\mathrm{f} 0} \quad=$ the intrinsic concentration of liquid in foam at the liquid-foam interface
$\left[\mathrm{kg} / \mathrm{m}^{3}\right]$
$D \quad=$ sphere equivalent diameter defined by Eq. (4)
$D_{\text {iep }} \quad=$ sphere-equivalent diameter at $\mathrm{pH} 4.6$ (i.e.p.)
$\mathrm{k} \quad=$ Boltzmann constant
$K=$ adsorption equilibrium constant
$\left[\mathrm{m}^{3} / \mathrm{kg}\right]$
$L \quad=$ Avogadro's number
$M_{\mathrm{w}} \quad=$ molecular weight
$[\mathrm{kg} / \mathrm{mol}]$
$r_{\mathrm{s}} \quad=$ solute radius
$r_{\mathrm{p}} \quad=$ pore radius
$R_{\text {eff }} \quad=$ effective radius of solute
$S_{\mathrm{b}} \quad=$ the production rate of bubble surface area
in the dispersion phase
$T=$ temperature
$U_{\mathrm{g}} \quad=$ superficial gas velocity
$W_{\mathrm{f}} \quad$ = volumetric flow rate of the liquid in foam
$W_{\mathrm{f} 0} \quad=$ the intrinsic volumetric flow rate of the liquid in foam at the liquid-foam interface within the column $\left[\mathrm{m}^{3} / \mathrm{s}\right]$
$X \quad=$ surface density of protein $\left[\mathrm{kg} / \mathrm{m}^{2}\right]$

Greek symbol 


$\begin{array}{llr}\varepsilon & =\text { dielectric constant } & {[-]} \\ \varepsilon_{0} & =\text { permittivity of free space } & {\left[\mathrm{C}^{2} /(\mathrm{J} \mathrm{m})\right]} \\ \varepsilon_{\mathrm{G}} & =\text { gas holdup } & {[-]} \\ \gamma & =\text { saturated adsorption density on bubble surface } & {\left[\mathrm{kg} / \mathrm{m}^{2}\right]} \\ \kappa & =\text { Debye length } & {\left[\mathrm{m}^{-1}\right]} \\ \lambda & =\text { a parameter defined by Eq. (5b) } & {[-]} \\ \mu_{\mathrm{L}} & =\text { liquid viscosity } & {[\mathrm{kg} /(\mathrm{m} \mathrm{s})]} \\ \rho_{\mathrm{G}} & =\text { gas density } & {\left[\mathrm{kg} / \mathrm{m}^{3}\right]} \\ \rho_{\mathrm{L}} & =\text { liquid density } & {\left[\mathrm{kg} / \mathrm{m}^{3}\right]} \\ \sigma_{\mathrm{s}} & =\text { surface charge density of solute } & {\left[\mathrm{C} / \mathrm{m}^{2}\right]}\end{array}$




\section{References}

[1] P. Sarkar, P. Bhattacharya, R.N. Mukerjea, M. Mukerjea, Biotechnol. Bioeng. 29 (1987) 934-940.

[2] L. Brown, G. Narsimhan, P.C. Wankat, Biotechnol. Bioeng. 36 (1990) 947-959.

[3] P. Bhattacharya, S.K. Ghosal, K. Sen, Sep. Sci. Technol. 26 (1991) 1279-1293.

[4] S.B. Mohan, L. Smith, W. Kemp, A. Lyddiatt, J. Inst. Brew. 98 (1992) 187-192.

[5] G.A. Montero, T.F. Kirchner, R.D. Tanner, Appl. Biochem. Biotechnol. 39/40 (1993) 467-475.

[6] H. Maruyama, A. Suzuki, H. Seki, J. Colloid Interface Sci. 224 (2000) 76-83.

[7] H.M. Schoen, Ann. N.Y. Acad. Sci. 137 (1966) 148-161.

[8] B.L. Karger, M.W. Miller, Anal. Chim. Acta 48 (1969) 273-290.

[9] K.S. Ng, J.C. Muller, C.C. Walden, J. WPCF 48 (1976) 458-472.

[10] S.D. Huang, H. Ho, Y. Li, C. Lin, Environ. Sci. Technol. 29 (1995) 1802-1807.

[11] S.G. Beheir, M. Aziz, J. Radioanal. Nucl. Chem. 209 (1996) 75-89.

[12] J.D. Firebaugh, C.R. Daubert, Int. J. Food Properties 8 (2005) 243-253.

[13] V.C. Sgarbieri, Brazilian J. Food Technol. 8 (2005) 43-56.

[14] P.J. Halling, CRC Critical Reviews in Food Sci. Nutrit. 15 (1981) 155-203.

[15] O.S. Lawal, Food Chem. 86 (2004) 345-355.

[16] C.C. Sánchez, J.M.R. Patino, Food Hydrocolloids 19 (2005) 407-416. 
[17] S. Rouimi, C. Schorsch, C. Valentini, S. Vaslin, Food Hydrocolloids 19 (2005) 467-478.

[18] E.A. Foegeding, P.J. Luck, J.P. Davis, Food Hydrocolloids 20 (2006) 284-292.

[19] N. Müller-Fischer, E.J. Windhab, Colloids and Surfaces A: Physicochem. Eng. Aspects 263 (2005) 353-362.

[20] Y.P. Nunez, A.V. Carrascosa, R. Gonzáles, M.C. Polo, A.J. Martínez-Rodríguez, J. Agric. Food Chem. 53 (2005) 7232-7237.

[21] A. Suzuki, H. Maruyama, J. Colloid Interface Sci. 238 (2001) 54-61.

[22] O.H. Lowry, N.J. Rowebrough, A.L. Farr, R.J. Randall, J. Biol. Chem. 193 (1951) 265-275.

[23] A. Suzuki, H. Maruyama, H. Seki, T. Hayashi, J. Chem. Eng. Jpn. 28 (1995) 115-117.

[24] J.R. Hunter, P.K. Kilpatrick, R.G. Carbonell, J. Colloid Interface Sci. 137 (1990) 462-481.

[25] L. Razumovsky, S. Damodaran, J. Agric. Food Chem. 49 (2001) 3080-3086.

[26] A. Suzuki, K. Yasuhara, H. Seki, H. Maruyama, J. Colloid Interface Sci. 253, (2002) 402-408.

[27] S.I. Ahmad, Separation Sci. 10 (1975) 689-700.

[28] F. Uraizee, G. Narsimhan, Separation Sci. 30 (1995) 847-881.

[29] T. Matsumoto, H. Inoue, J. Colloid Interface Sci. 160 (1993) 105-109.

[30] P.E. Stein, G.W. Leslie, J.T. Finch, D.J. Maclaughlin, R.W. Carrell, Nature 347 (1990) 99-102.

[31] C. Tanford, S.A. Swanson, W.S. Shore, J. Am. Chem. Soc. 77 (1955) 
6414-6421.

[32] G. Scatchard, J.S. Coleman, A.L. Shen, J. Am. Chem. Soc. 79 (1957) $12-20$.

[33] N.S. Pujar, A.L. Zydney, J. Chromatography A 796 (1998) 229-238.

[34] R.K. Cannan, A. Kibrick, A.H. Palmer, Ann. N. Y. Acad. Sci. 41 (1941) 243-266.

[35] "Biochemical Data Book I", (The Japanese Biochemical Society, Ed.), p. 231, Tokyo-Kagaku-Dohjin, Tokyo, 1979.

[36] A.D. Nisbet, R.H. Saundry, A.J.G. Moir, L.A. Forthergill, J.E. Fothergill, Eur. J. Biochem. 115 (1981) 335-345.

[37] L. McReynolds, B.W. O'Malley, A.D. Nisbet, J.E. Forthergill, Nature 273 (1978) 723-728. 


\section{Captions of figures and tables}

Fig. 1. Schematic drawing of experimental setup for continuous foam separation.

Fig. 2. Adsorption isotherms of ovalbumin at various pHs. Solid lines in this figure are calculated using $K$ and $\gamma$. The values of $K$ and $\gamma$ are listed in Table 1 .

Fig. 3. Variation of $D / D_{\text {iep }}$ with pHs. Solid line is the calculated value by using Eqs. (6a), (6b), (7) and (8).

Table 1 Adsorption parameters and the sphere-equivalent diameter (effective diameter) for ovalbumin at various $\mathrm{pHs}$

Table 2 Type and Number of Amino acids including ovalbumin 


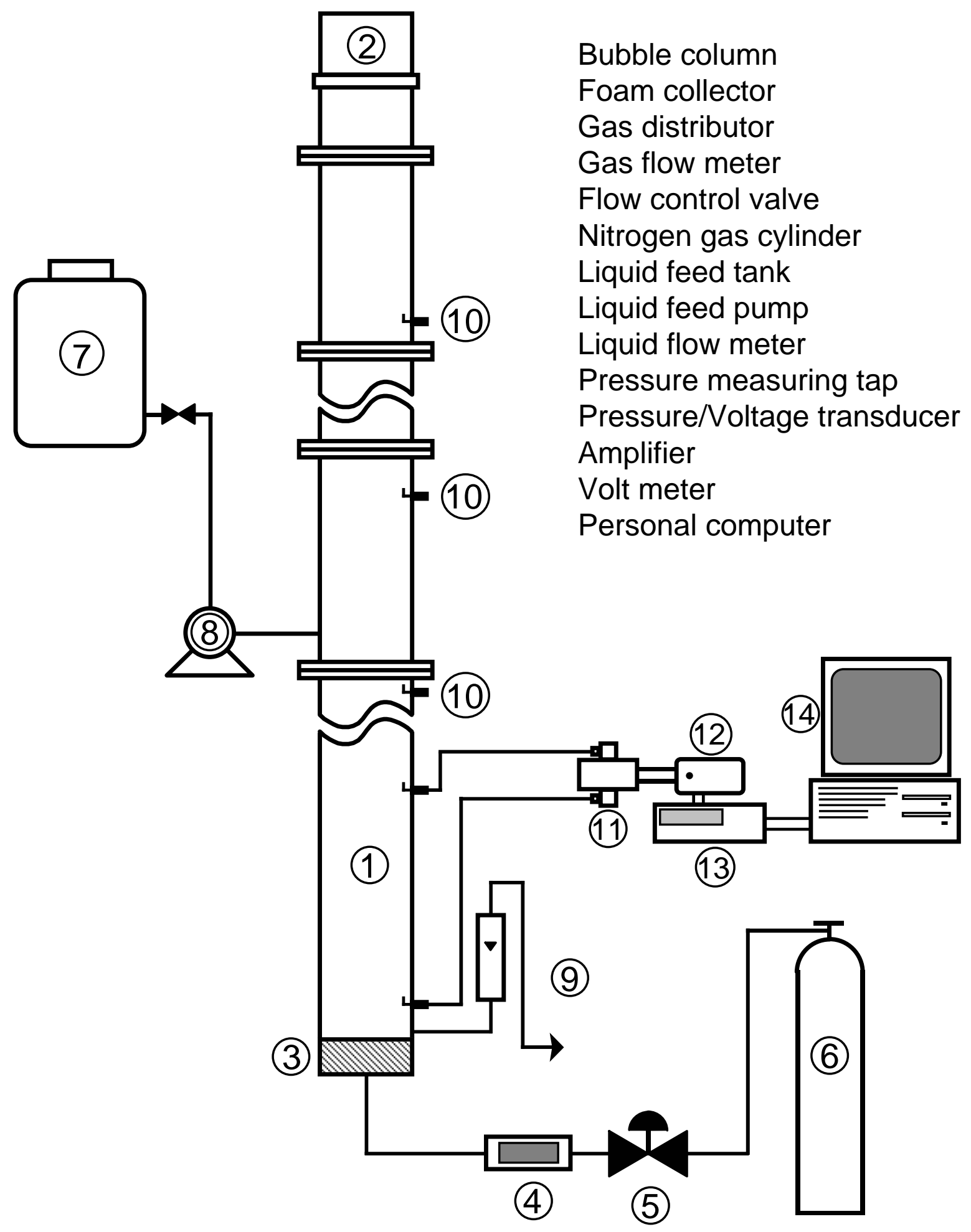

Fig. 1. Schematic drawing of experimental setup for continuous foam separation. 


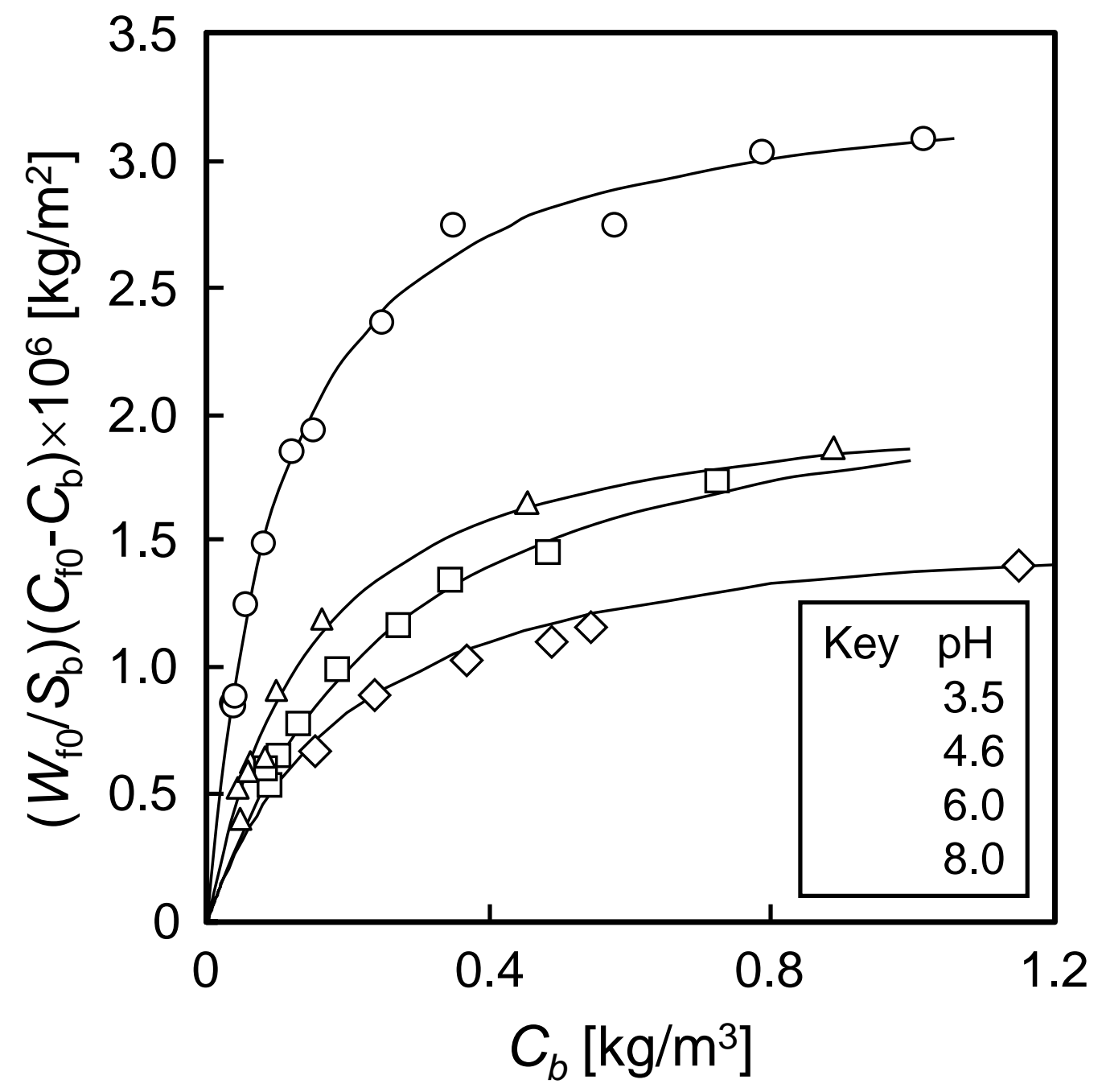

Fig. 2. Adsorption isotherms of ovalbumin at various pHs. Solid lines in this figure are calculated using $K$ and $\gamma$. The values of $K$ and $\gamma$ are listed in Table 1. 


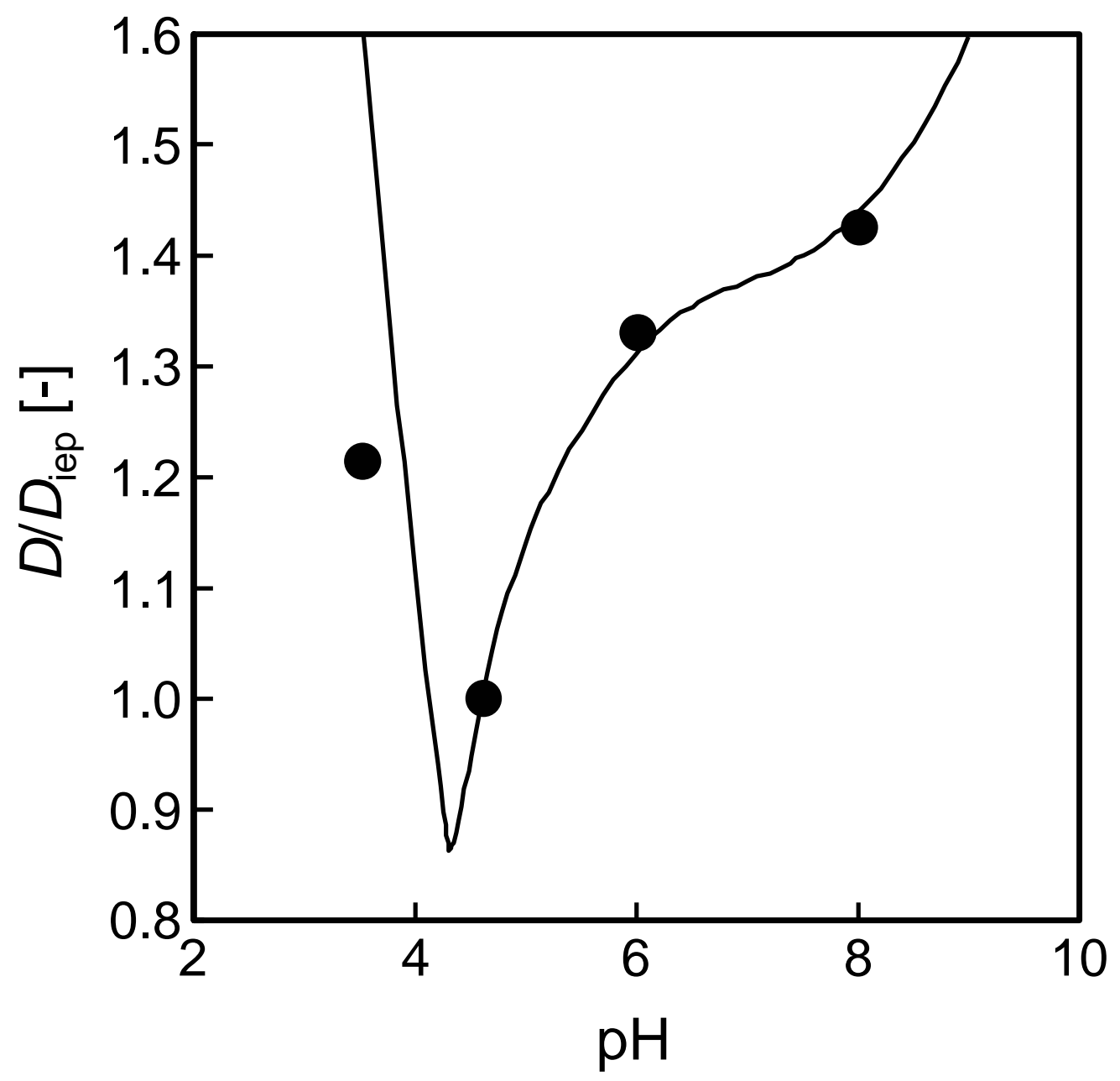

Fig. 3. Variation of $D / D_{\text {iep }}$ with pHs. Solid line is the calculated value by using Eqs. (6a), (6b), (7) and (8). 
Table 1

Adsorption parameters and the sphere-equivalent diameter (effective diameter) for ovalbumin at various $\mathrm{pHs}$.

\begin{tabular}{cccc}
\hline $\mathrm{pH}$ & $\gamma \times 10^{6}\left[\mathrm{~kg} / \mathrm{m}^{2}\right]$ & $K \times 10^{2}\left[\mathrm{~m}^{3} / \mathrm{kg}\right]$ & $D[\AA]$ \\
\hline 3.5 & 2.30 & 3.94 & 61.2 \\
4.6 & 3.39 & 10.1 & 50.4 \\
6.0 & 1.92 & 8.72 & 67.0 \\
8.0 & 1.67 & 4.84 & 71.9 \\
\hline
\end{tabular}


Table 2

Type and Number of Amino acids including ovalbumin

\begin{tabular}{lrr}
\hline \multicolumn{1}{c}{ Type } & Number $(N)^{\mathrm{a}}$ & $\mathrm{p} K^{a}$ \\
\hline$\beta, \gamma$-Carboxyl & 51 & 3.98 \\
Imidasole & 5 & 5.91 \\
$\varepsilon$-Amino & 22 & 10.51 \\
Phenolic & 10 & 9.95 \\
Guanidine & 14 & 12.00 \\
Thiol & 4 & 8.50 \\
\hline
\end{tabular}

a Refs. [34-37] 